\title{
Practical training: from ideas to optical devices
}

\section{Nadezhda Tolstoba, Anna Voznesenskaya, Maria Orekhova}

Nadezhda Tolstoba, Anna Voznesenskaya, Maria Orekhova, "Practical training: from ideas to optical devices," Proc. SPIE 9946, Optics Education and Outreach IV, 994614 (27 September 2016); doi: 10.1117/12.2238027

SPIE Event: SPIE Optical Engineering + Applications, 2016, San Diego, California, United States 


\title{
Practical training: from ideas to optical devices \\ Nadezhda Tolstoba, Anna Voznesenskaya, Maria Orekhova ITMO University, 49 Kronverksky av., St. Petersburg, 197101, Russian Federation
}

\begin{abstract}
The Student Research Laboratory for Optical Engineering in the ITMO University is the space for self-education and skills improving in the field of optics, optical engineering, photonics, light engineering for all the people: for students, graduates and experts. It is the space for realization of project for the motivated groups of people.
\end{abstract}

Keywords: optics, education, practical skills, optical projects, equipment, design

\section{INTRODUCTION}

The laboratory was created by students for students [1]. Participants of this laboratory are an initiative group of students, who are involved in science communication, want to become more competent in their field and related fields, and develop practical skills in the professional area that is demanded urgently at the job market [2]. Thus, it appears that the process of education for both sides is profitable: for example, when a senior student teaches an undergraduate student. And both of them get skills, abilities and knowledge, which are interesting for them.

\section{ABOUT THE LABORATORY}

Self-education is a complicated process. Students cannot always study complex courses by themselves. And there are many reasons for this: from plain ignorance till difficulties of theory perception. But in the most common case the reason of misunderstanding is student's lack of practical skills, which are not compensated with labs, because serious equipment is not available for students and virtual labs do not give a complete picture/vision?.

And it appears that complicated subject which a student passes, could be understood very easily, if one learned something practical but dry and unfriendly theory from a textbook.

Our laboratory is willing to help in these issues itself and in cooperation with teachers of ITMO University. There are some examples of courses for which members of laboratory develop equipment and conduct classes:

- basic optics;

- geometrical optics;

- computer optics;

- optical design.

\section{ABOUT PRACTICAL COURSES}

In the laboratory we have the self-developed equipment, which is used for demonstrating of principles of internal devices, showing different optical and light experiments and phenomena. It is possible to try all devices and components in practice and "play" with it.

The most popular example of studying in the Lab is the Keplerian and Galilean telescopic systems (fig. 1). The students are explained about what the telescopic system is, its features, application, what is the difference between Keplerian and Galilean telescopes. In the end of the lesson the student is given with the opportunity to assemble and align the telescopic system, to determine its paraxial characteristics, and the mutual influence of the size and parameters of elements in the resulting scheme. It is important to note that student takes it as a game - he or she is interested in calculating the distance where lenses should be located, and in forming of a parallel beam by using a telescopic system.

Optics Education and Outreach IV, edited by G. Groot Gregory, Proc. of SPIE Vol. 9946, 994614

(C) 2016 SPIE · CCC code: 0277-786X/16/\$18 - doi: 10.1117/12.2238027 

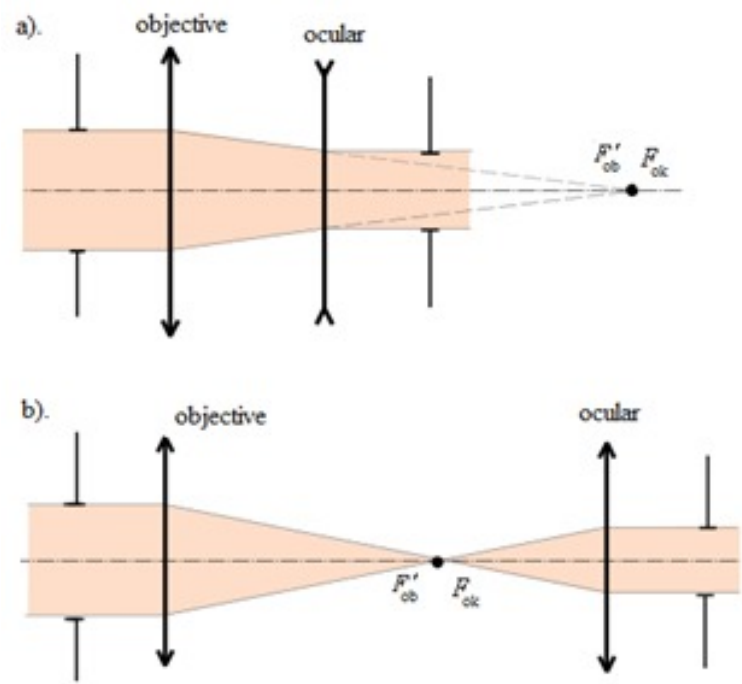

Fig. 1. Galilean (a) and Keplerian (b) telescopic system

Tasks are divided by a level of complexity:

1. In the simplest case a student is getting the values of lenses focal length. And then he calculates the distance between lenses and in the case of right calculation the student gets the parallel light beam. Also in the process of telescope aligning the student learns how to distinguish in practice a parallel and non-parallel light beam.

2. In the case of Keplerian telescopic system design, a student learns to understand where the intermediate image plane located is. Also the mentor explains how this intermediate image plane could be applied (scales, grids etc). Additionally on a blackboard optical circuits of these systems are demonstrated, which also complement the student's knowledge and teaches him to understand schematics.

3. In fig. 2 is shown that a member of the Laboratory teaches two girls to align a Galilean telescope during an optical quest. The aim of this quest is to assemble a photo transmitter and receiver. Only in case of a right assembling, participants of the quest could win a lens they need to assemble the device.

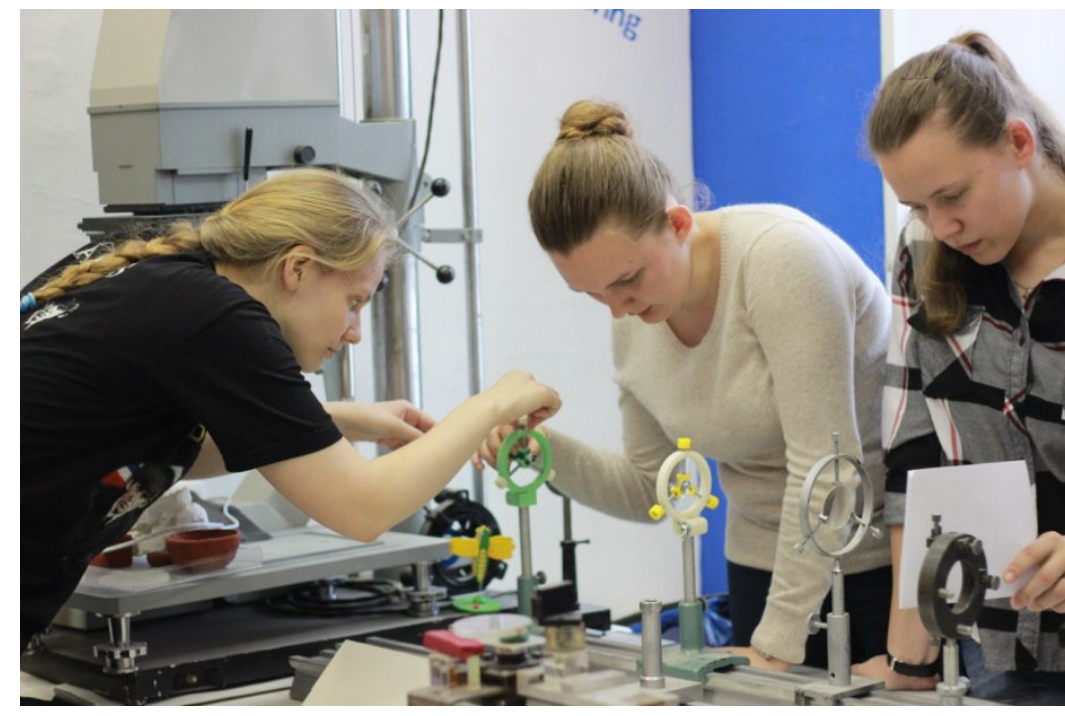

Fig. 2. The telescopic system. An nteractive game

Thus the development and assembling of telescopic systems allow to study and test in practice optical parameters and feachers. 


\section{UNITS DEVELOPED BY LABORATORY MEMBERS}

The Lab members design or even invent devices and parts to make working process more comfortable or laboratory experiments more visual. An example of a simple experience that is repeated every year in the laboratory - the creation of the camera-obscura (Fig.3) as a simplest camera.

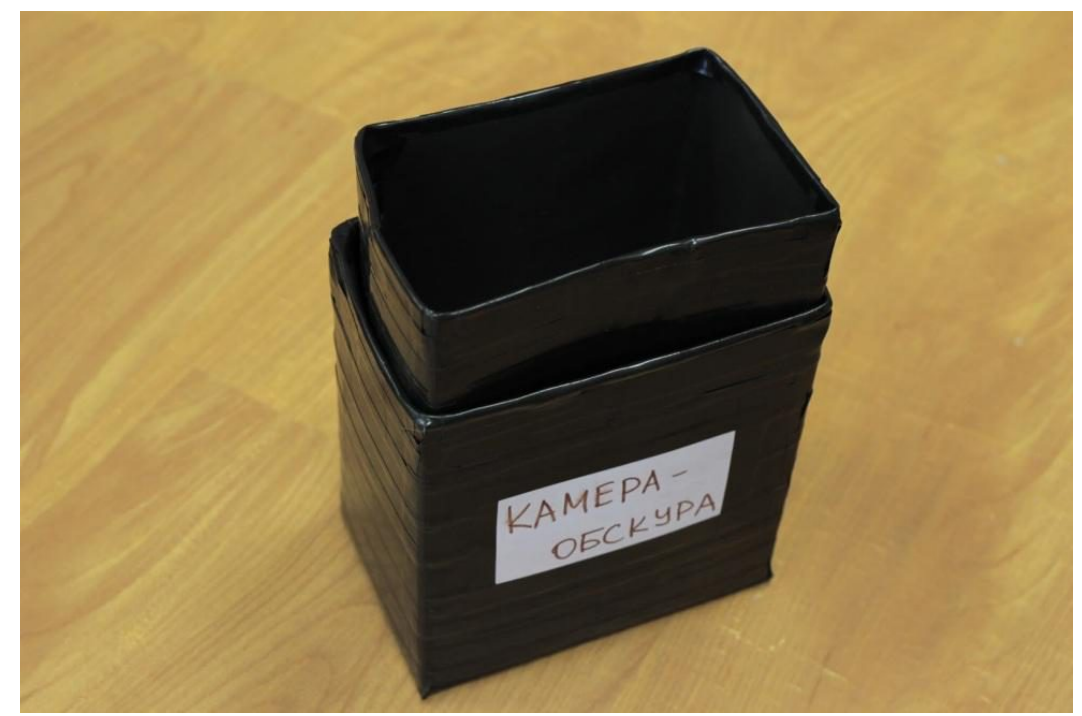

Fig. 3. The camera-obscura

As a rule, training equipment should be not only understandable, but also portable, as the laboratory often takes part in various scientific and educational events and festivals. Thus, the projects must be simply assembled and disassembled, and it provokes the creation of some elements or entire stands.

Due to these circumstances, it was created a few interesting projects for the lab:

- holders for the optical elements;

- a laser light source;

- an adjustment setting for the light source "laser pointer".

Pictures of these devices are shown below (fig.4).

\section{Holders for the optical elements}

Mounts for the optical elements (lenses, prisms) are designed, 3D-printed and actively used.

This laboratory equipment for assembling an optical system of the simplest level, intended for use in labs, interactive sessions and so on. Due to the simplicity and adaptability, this set of holders solves a number of problems:

- making of simple schemes;

- creation of the necessary laboratory equipment;

- the finance question - this version of holders is extremely cheap;

- the demonstration of the basic optics experiments.

\section{The laser light source}

The laser pointer for using in the Lab was developed (fig. 5). Also it can be charged through USB. This device was selfdesigned and created by using 3D-printers of our colleagues from OLIMP and now it is in totally use [3].

It is important to note that:

- This device reduces the consumption of expendable materials - batteries 
- it is an independent device;

- it can be quickly reproduced by Laboratory forces without any additional funds.

\section{The setting for the light source "laser pointer" with adjustment}

Before designing laser light source, shown in fig. 5, more simple type of laser pointer was in use. It is powered by batteries. The special mount (Fig. 6) has been developed for it.

There are three adjusting screws which let to direct the laser beam and to fix it in correct position. It was at the same time some kind of a training task, a designing process, also a process of rapid prototyping technology using, and a good technical decision.

And most important, all these devices are developed by considering an available equipment opportunities, thus, it can be easily made in the "field conditions", what repeatedly has been done by our members at the events and festivals.
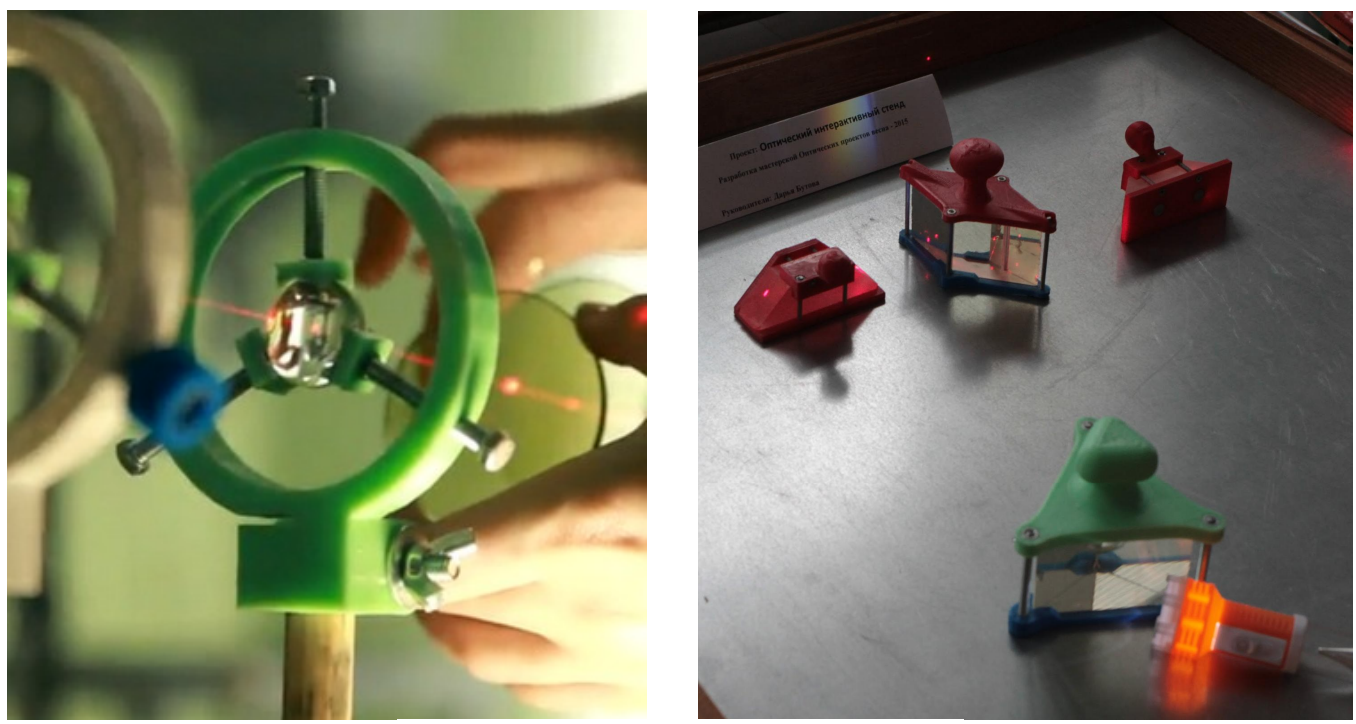

Fig. 4. The mounts for lenses and prisms

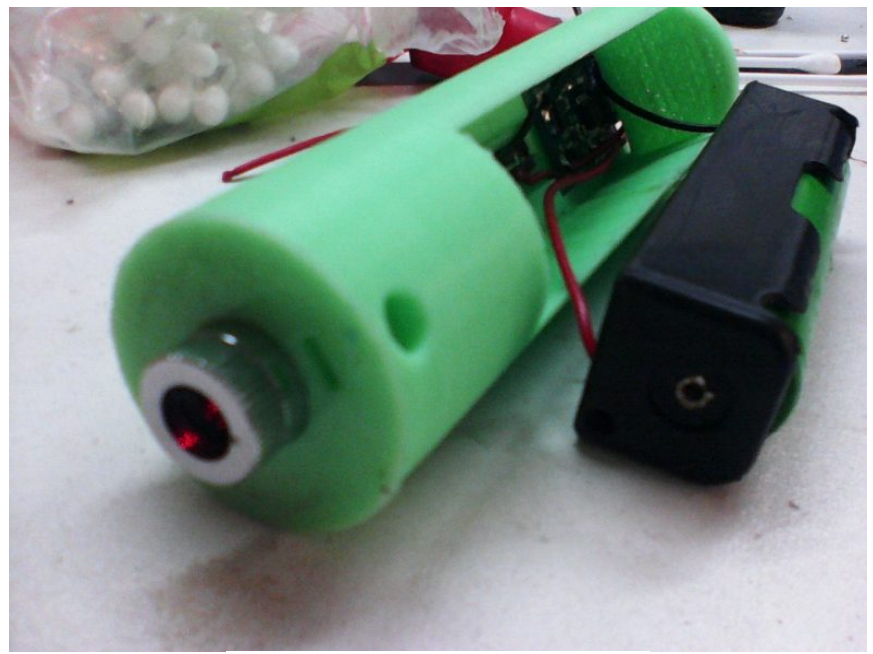

Fig. 5. The laser source mount 


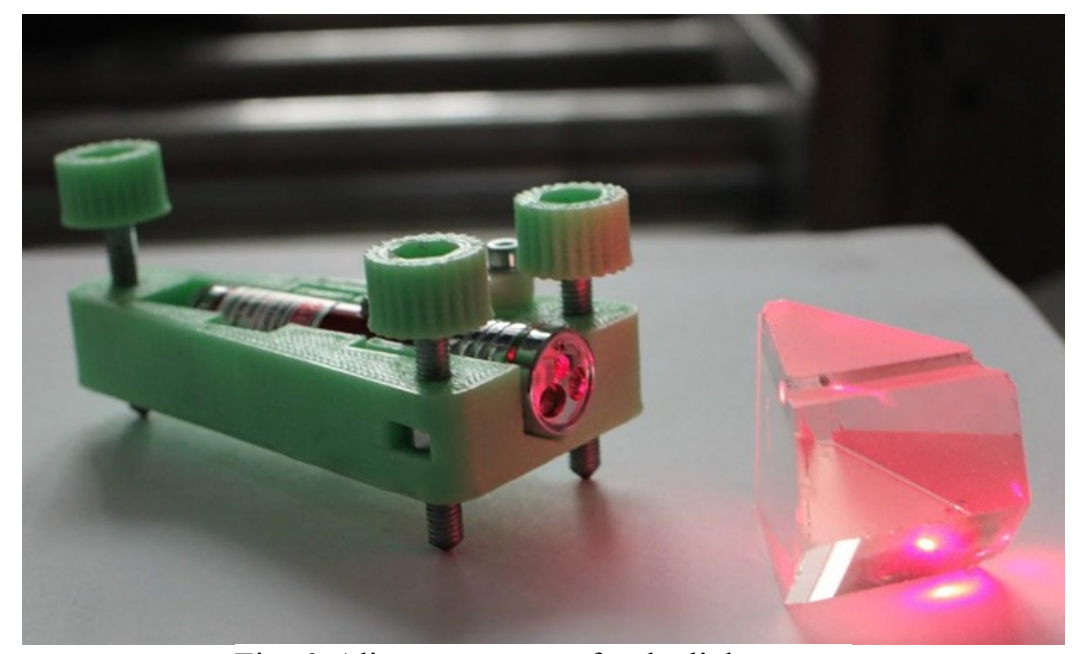

Fig. 6. Alignment mount for the light source

\section{CONCLUSION}

Thus, we would like to emphasize the role of practical skills in the educational process of the future qualified person, the employee, the team member. The main point in this case is the ability to test ideas in practice, the possibility of the devices design by using components and circuits based on the ideas developed in the team. This allows the team to continue working on more complicated and serious project, it develops a professional; it creates a professional-oriented person.

\section{REFERENCES}

[1] Tolstoba, N.D., Saitgalina, A.K., Abdula, P.A., Butova, D.V. "Student research laboratory for optical engineering," Proc. SPIE 9793, 97931Y (2015).

[2] Bakholdin, A., Kujawinska, M., Livshits, I., Styk, A., Voznesenskaya, A., Ezhova, K., Ermolayeva, E., Ivanova, T., Romanova, G., Tolstoba, N. "Double degree master program "Optical design"," Proc. SPIE 9793, 979307 (2015).

[3] Saitgalina, A.K., Mitiushkin, A.V., Tolstoba, N.D. "Research of limits of applicability of an open-source equipment for development the optical equipment kit," Proc. SPIE 9889, 98891W (2016). 